\title{
CRÍTICA DE LA NOCIÓN DEL AGENTE-DISTRIBUIDOR EN EL DERECHO COLOMBIANO Y SUS REPERCUSIONES JURÍDICAS*
}

\author{
Eduardo Salgado Figueroa**
}

Fecha de recepción: 16 de julio de 2015

Fecha de evaluación: 11 de diciembre de 2015

Fecha de aprobación: 2 de marzo de 2016

Artículo de reflexión

DOI: http://dx.doi.org/10.18359/prole.1974

Forma de citación: Salgado, E. (2016). Crítica de la noción del agente-distribuidor en el derecho colombiano y sus repercusiones jurídicas. Revista Prolegómenos Derechos y Valores, 19, 38, 127-143. DOI: http://dx.doi.org/10.18359/ prole.1974

\section{Resumen}

Este artículo devela la noción y los alcances de lo que se conoce como agente-distribuidor en Colombia, con el propósito de evidenciar su impertinencia acorde con lo dictado por la jurisprudencia, conceptos foráneos y la propia doctrina, de lo cual se desprende la incipiente propuesta de una nueva relectura sobre algunas temáticas centrales en materia de agencia y distribución mercantil. Se empleó el método hermenéutico analítico para entender la naturaleza de esta figura, estudiando los elementos de promoción y explotación, la teoría del riesgo negocial utilizada en los contratos de comercialización y un breve análisis de la concurrencia contractual.

\section{Palabras clave:}

Agente, distribuidor, promoción, explotación.

\section{CRITICISM OF THE NOTION OF THE AGENT-DISTRIBUTOR IN COLOMBIAN LAW AND ITS LEGAL IMPLICATIONS}

\section{Summary}

This article unveils the notion and scope of what is known as agent-distributor in Colombia, with the purpose of evidencing his impertinence in accordance with what is stated by the jurisprudence, foreign concepts and own doctrine, which suggests the incipient proposal for a new reinterpretation of some central themes related to agency and commercial distribution. It was

\footnotetext{
El presente artículo es resultado de la investigación efectuada por el autor para optar por el título de magíster en Derecho de la Universidad Sergio Arboleda (Bogotá, Colombia).

** Magíster en Derecho de la Universidad Sergio Arboleda (Bogotá, Colombia). Abogado y especialista en Derecho Comercial de la Universidad Libre (Cartagena, Colombia). Profesor del Programa de Derecho de la Universidad Tecnológica de Bolívar (Cartagena, Colombia). Correo electrónico: esalgado@unitecnologica.edu.co
} 
used the analytical hermeneutic method to understand the nature of this figure, studying the elements of promotion and exploitation, the business risk theory used in marketing contracts and a brief analysis of the contractual concurrency.

\title{
Keywords:
}

Agent, distributor, promotion, exploitation.

\section{CRÍTICA DA NOÇÃo DO AGENTE-DISTRIBUIDOR NO DIREITO COLOMBIANO E AS SUAS REPERCUSSÕES JURÍDICAS}

\begin{abstract}
Resumo
Este artigo revela a noção e os alcances do que se conhece como agente-distribuidor na Colômbia, com o propósito de evidenciar a sua impertinência de acordo com o ditado pela jurisprudência, conceitos forâneos e a própria doutrina, de onde se desprende a incipiente proposta de uma nova releitura sobre algumas temáticas centrais em matéria de agência e distribuição mercantil. Foi empregado o método hermenêutico analítico para entender a natureza desta figura, estudando os elementos de promoção e exploração, a teoria do risco negocial utilizada nos contratos de comercialização e uma breve análise da concorrência contratual.
\end{abstract}

\section{Palavras-chave:}

Agente, distribuidor, promoção, exploração

\section{Introducción}

En Colombia desde la regulación del contrato de agencia mercantil se fijó una figura que permite la desnaturalización del contrato de distribución mercantil y el propio contrato de agencia: el agente-distribuidor. De esta manera se han establecido discusiones alrededor de dicho agentedistribuidor en el seno de la doctrina nacional y la jurisprudencia. El argumento problemático es simple, consiste en que el agente está habilitado como distribuidor siempre que cumpla con los elementos de promoción y explotación, lo que hace manifestar consecuencias jurídicas adversas en los contratos de agencia comercial y distribución mercantil, tales como el incorrecto entendimiento de la promoción o la explotación, además de la indebida aplicación del riesgo negocial.

Es necesario abordar lo referente al agentedistribuidor, darle explicación y relacionarlo con la desnaturalización en materia de aplicación contractual en cuanto a la agencia o la distribución mercantil. Por ello es esencial entender la figura del agente-distribuidor, la controversia que causa y el estado en que se encuentra desde la visión colombiana, con el propósito de demostrar la impertinencia de la aludida figura y estudiarla más a fondo para comenzar a releer lo establecido en el artículo 1317 del Código de Comercio para la agencia mercantil nacional en cuanto a sus alcances.

En definitiva, se presentará una visión jurídica crítica utilizando un método hermenéutico analítico, apoyado de elementos de derecho comparado para tratar de demostrar la impertinencia del agente-distribuidor en Colombia. Para tal fin se examina la promoción, la explotación, el riesgo negocial y la concurrencia contractual de la agencia con otras figuras, según lo que expone la jurisprudencia colombiana. En líneas generales 
se pretende demostrar que la completa desestimación del agente-distribuidor va acorde con la historia, la jurisprudencia y con lo desplegado por la doctrina nacional y extranjera.

\section{A. Antecedentes de la aplicación del contrato de agencia comercial en Colombia}

El Código de Comercio de 1887 estableció la agencia, tal como manifiesta Narváez (1976) cuando la misma norma prescribió en el libro primero De los comerciantes y los agentes de comercio; además el artículo 20 enumeraba a las agencias de negocios. Aunque autores como Cárdenas (1984) opinan que la agencia de negocios no era propiamente la agencia mercantil de hoy en día, entre muchas razones por no compartir la estabilidad que se requiere en la agencia comercial.

Tomamos como punto de partida la utilización de varias figuras -tales como la representación o la distribución- para dar entrada a los empresarios de cara a la conquista de clientela y su mantenimiento. De igual manera se expresa Cárdenas (1984):

Se intentaba proteger a los comerciantes nacionales contra los abusos de otros empresarios, generalmente extranjeros, con quienes habían celebrado contratos de representación o distribución para promover y vender productos en el territorio colombiano o en determinadas partes de este. Ocurría a menudo que una vez que el comerciante había logrado conquistar una clientela, establecer un mercado, acreditar un producto, el empresario revocaba el contrato, haciendo uso de una facultad consagrada o no en este, y en seguida le concedía a otro comerciante la representación, en condiciones más favorables para aquel, o la asumía por sí mismo, con graves perjuicios para el comerciante nacional (p. 14).

En el mismo sentido Pérez (citado en López, 2011) asegura que había fraudes a las obliga- ciones laborales que exigían a empresarios la constitución de sociedades y posteriormente la celebración de contratos de representación y distribución.

[...] se había popularizado el mecanismo de obligar al empleado a constituir una sociedad, con la cual celebraba el empresario un contrato de representación y distribución, eludiendo así el pago de las prestaciones sociales y, en general, la legislación laboral (Pérez, citado en López, 2011, p. 9).

Estos antecedentes sobre la utilización de la distribución y la comprensión de la agencia de negocios llevan a concluir que por economía, y quizá por falta de regulación extranjera para la época del contrato de distribución, resultaba sencillo redactar un nuevo artículo de tal forma que todos los supuestos de hecho que se podrían presentar en el marco de los contratos de intermediación o comercialización quedaran cobijados en la ley, en tal virtud, nace el artículo 1317 del Código de Comercio de 1971.

\section{B. La explotación y la promoción como elementos de la agencia comer- cial y la distribución mercantil}

\section{Definición de la agencia comercial}

La agencia comercial es un negocio jurídico estudiado con amplitud en el mundo, tan prolífico que hay discrepancias en su tipificación: en muchos países es una figura atípica, y en otros, un contrato típico dentro de su ordenamiento jurídico. A continuación se plasmarán algunas definiciones legales extranjeras con el propósito de extraer consideraciones que servirán para hacer una breve comparación con la legislación nacional, e ir sacando conclusiones a partir de ciertos elementos objeto de sus análisis. Sobre las distintas reglamentaciones a la figura de la agencia Puelma declara:

Los intermediarios en la actividad económica son conocidos al menos desde el tiempo de 
los romanos. A principio del siglo pasado, época de la dictación del Código de Comercio Francés y de los que siguieron sus aguas, no estaba estructurada la agencia o representación comercial y menos aún los contratos de concesión mercantil, distribución y franchising. Sin embargo, ya había atisbos de ellos; por ejemplo, el Código de Comercio chileno en el N. 7 del Art. 3 menciona las agencias de negocios, que tienen relación con el tema. [...] Con posterioridad a Alemania, las legislaciones de Italia, Francia y Bélgica trataron sobre esta figura jurídica. En Latinoamérica, Brasil, Bolivia y Colombia también lo hicieron. Además el Código italiano reglamentó el contrato de distribución (1991, p. 63).

En España, por ejemplo, la agencia escoge la siguiente definición:

Por el contrato de agencia una persona natural o jurídica, denominada agente, se obliga frente a otra de manera continuada o estable a cambio de una remuneración, a promover actos $\mathrm{u}$ operaciones de comercio por cuenta ajena, o a promoverlos y concluirlos por cuenta y en nombre ajenos, como intermediario independiente, sin asumir, salvo pacto en contrario, el riesgo y ventura de tales operaciones (ley 12/1992).

Al inicio la armonización en este tema fue ordenada para la época por el Consejo de las Comunidades Europeas a través de la directiva 86/653/CEE (1986) que en su artículo primero define al agente comercial como:

[...] toda persona que, como intermediario independiente, se encargue de manera permanente ya sea de negociar por cuenta de otra persona, denominada en lo sucesivo el "empresario", la venta o la compra de mercancías, ya sea de negociar y concluir estas operaciones en nombre y por cuenta del empresario.
En Francia por su parte, el agente es un mandatario independiente que actúa en nombre y por cuenta de otros sujetos.

El agente es un mandatario que, como profesional independiente, sin estar vinculado por un contrato de arrendamiento de servicios, estará encargado, de modo permanente, de negociar y, eventualmente, de ultimar contratos de venta, de compra, de alquiler o de prestación de servicios en nombre y por cuenta de productores, de empresarios, de comerciantes o de otros agentes comerciales. Puede ser una persona física o jurídica (Código de Comercio francés, capítulo IV, art. L134-1).

En Brasil la ley 10406 de 10 enero de 2002 regula el contrato de agencia y distribución en su capítulo XII artículo 710, el cual consigna la disposición de las cosas como punto de diferenciación entre lo que debe ser un agente y un distribuidor: el agente actúa por cuenta ajena y no tiene a disposición la cosa, mientras que el distribuidor debe tener a su disposición las cosas que resultarán negociadas.

En Argentina la definición de contrato de agencia se desprende del proyecto de unificación del Código Civil y el Código de Comercio:

En el contrato de agencia una parte denominada agente, se obliga a promover negocios por cuenta de otra denominada preponente o empresario, de manera estable, continuada $e$ independiente, sin que medie relación laboral alguna, mediante una retribución. El agente es un intermediario independiente, no asume el riesgo de las operaciones, ni representa al preponente. El contrato deberá instrumentarse por escrito (art. 1479).

El profesor argentino Osvaldo Marzorati (2008) entiende la agencia como un "contrato por medio del cual una parte, denominada 'comitente', le encarga a otra, llamada 'agente', la promoción de negocios por su cuenta y orden" (p. 13). 
En Colombia el contrato de agencia está fuertemente influenciado por el Código Civil italiano de 1942 (Camacho, 2008), del cual podemos extraer similitudes que nos ayuden a comprender más lo codificado en nuestro país. En todo caso, Colombia tiene su propia y particular tipificación de la figura, a la cual vale la pena dedicarle más estudio a partir de su concepto; así reza lo prescrito en nuestro Código de Comercio:

Por medio del contrato de agencia, un comerciante asume en forma independiente $y$ de manera estable el encargo de promover o explotar negocios en un determinado ramo y dentro de una zona prefijada en el territorio nacional, como representante o agente de un empresario nacional o extranjero o como fabricante o distribuidor de uno o varios productos del mismo. La persona que recibe dicho encargo se denomina genéricamente agente (art. 1317).

La particularidad en la anterior redacción es sin duda la de encargar al agente la promoción o explotación en calidad de distribuidor; esto no compagina con las propuestas legislativas y doctrinales extranjeras, pues las mismas no pretenden que el agente pueda actuar como distribuidor.

Lo expuesto es lo que se conoce como agentedistribuidor, el cual hace necesario un breve repaso de algunas características, en especial la promoción, la explotación y lo que se debe entender por negociación en el marco de la agencia y la distribución, ya que dichos elementos ejercen funciones distintas que ayudarán a demostrar cuán erróneo es mantener la figura del agente-distribuidor.

\section{La promoción o negociación y su relación directa con la agencia comercial}

En cuanto a su formación y existencia jurídica en el derecho de los negocios la agencia comercial tiene que evocar, entre otros elementos esenciales, a la promoción o explotación, como por ejemplo, cuando se manifiesta que la agencia es un contrato a cumplirse por cuenta de otro, pero a través de un encargo de promoción (Arrubla, 2004).

Cabe aclarar que en otros países como Francia, el elemento destacado es la negociación y no la promoción. De la misma manera así lo estima la directiva 86/653/CEE (1986). Para la agencia colombiana la negociación basta entenderla como un término doctrinal que comprende la promoción y la conclusión de los negocios, por lo que no significa explotar en ningún sentido, o lo mismo, no abarca la explotación per se; de tal suerte que si promover ha de tener alguna relación con los negocios jurídicos de agencia y distribución, no cabría duda que sería únicamente con la agencia mercantil.

Si echamos un vistazo al artículo 1317 del Código de Comercio colombiano no hay mención a la palabra negociar, pero sí a la de promoción, en cuanto se eleva como uno de los aspectos cardinales para dicha figura. Conviene entonces saber cuál es el significado jurídico que se le ha dado a los términos promover o explotar, sin perjuicio de sus definiciones individuales, pues se ha entendido en la doctrina que estos están íntimamente ligados atendiendo a la función de intermediación que caracteriza a la agencia. Para Cardozo (citado en López, 2011):

[...] el encargo de promocionar o explotar un negocio implica, necesariamente, una modalidad de intermediación diferente a la del mandato y la comisión. En la agencia comercial la intermediación no es para uno o varios actos, sino que va formando una cadena a través de la cual se persigue vincular una clientela, acreditar una marca, ampliar y mantener constante un mercado, etc., al paso que en el mandato las relaciones entre el mandatario y cliente son ocasionales y esporádicas, ya que finalizado el encargo, termina su relación con mandante y cliente (p. 17).

De la misma manera lo entiende el profesor Pérez (citado en López, 2011) al manifestar que el encargo de "promover o explotar negocios tiene 
como fin conquistar, ampliar o reconquistar un mercado"1 (p. 18).

Ciertamente la intermediación es una función jurídica de caracterización, en cuanto comporta ampliar, conquistar y mantener un mercado y su clientela, dando así una significación doctrinal a los dos términos antes aludidos, lo que a voces de Schmitt (1996) sería un compuesto conceptual del cual habría que determinar si pertenece o no al grupo de las buenas palabras combinadas. En este sentido, promover o explotar lo podríamos catalogar como un compuesto conceptual que sirve netamente para darle una función jurídica y económica al contrato de agencia comercial.

Hay que reconocer que lo plasmado hasta aquí no se acompasa enfáticamente con las definiciones de cada uno de esos elementos, ni con la redacción de dichos términos provenientes del artículo 1317 del Código de Comercio, en cuanto los separa una conjunción disyuntiva que denota alternativa o exclusión de los elementos. Observemos sus definiciones: por promoción se entiende el "conjunto de actividades cuyo objetivo es dar a conocer algo o incrementar sus ventas" (Diccionario de la RAE). Y por explotar el "sacar utilidad de un negocio o industria en provecho propio" (Diccionario de la RAE).

De esta manera observamos que explotar tendrá relación única y exclusiva con el contrato de distribución por no tenerlo con la agencia, ya que sacar utilidad en provecho de la agencia es sustancialmente imposible, dado el carácter intermediario que arropa este contrato, el cual está encaminado únicamente a promover, es decir: ampliar, conquistar y mantener el mercado y la clientela de otro empresario.

Siempre que se acepte un entendimiento conjunto por la unión de estos elementos aludidos o la definición individual de cada una de estas palabras, fuerza es concluir que cualquiera de las

En la misma concepción se puede ver el laudo arbitral Roberto Cavelier \& Cía Ltda. Flota Mercante Grancolombiana, 1 de julio de 1992. dos nos permite observar que no es jurídicamente aceptado que el agente saque provecho o utilidad del encargo dado por el empresario. Pero en el caso colombiano al parecer sí puede promover o explotar como lo entiende la doctrina nacional.

Por último, hay opiniones como la de Suescún (2003) que enarbolan la promoción por cuenta $y$ en beneficio del agenciado como punto de partida para permitir el agente-distribuidor ${ }^{2}$; se infiere que podría presentarse aquella figura si también se concreta en la configuración de la agencia el elemento por cuenta y en beneficio del encargante, que por supuesto aunque el autor no lo exprese de modo tajante da permiso al agente-distribuidor en su exposición. Aunque se admita un elemento por cuenta que se encamina a beneficiar jurídica y económicamente al empresario, no se puede tener como pilar para que con su sola aparición dentro del contrato de agencia dé cabida a la figura perjudicial del agente-distribuidor.

\section{Definición de la distribución mercantil}

La función económica de la distribución puede ser similar a la de la agencia, en este caso también se quiere ampliar el mercado y llegar a sitios inexplorados para que la marca del producto adquiera notoriedad y con ello un valor económico. El fabricante está ligado con todo el proceso de posicionamiento de su marca en los mercados, y para ello necesita la ayuda de agentes encargados de la colocación de los productos confiando en su organización empresarial independiente, distribuidores en sentido lato.

La distribución entonces, de manera simplificada, se da a partir de un contrato de ventas continuo, donde hay exclusividad o no, o también desde la transformación de una agencia, cuando el agente se hace cargo de los riesgos de los productos del fabricante, a nombre propio y por su cuenta (Baldi, 1987). La jurisprudencia argentina lo explica así:

2 En igual sentido encontramos a Tamayo (1995), García (2001) y Arrubla (2004) 
[...] el contrato de distribución comercial trata de una relación contractual entre dos empresas jurídicamente independientes, o sea entre dos organizaciones autónomas, que se distinguen claramente: Una produce bienes o servicios y la otra se ocupa de comercializarlos asumiendo los riesgos propios de su actividad, ello sin que medie un vínculo societario o laboral, aunque pueda haber una sumisión técnica o económica [...]. Es en definitiva, una modalidad de actuación interempresarial de sujetos jurídicamente autónomos pero ligados contractualmente en una actividad mercantil integrada, por lo cual un fabricante o productor deriva la labor de comercialización en uno o varios vendedores regulando su actuación en el mercado para potenciar un mutuo beneficio [...]. Más específicamente: en el contrato de distribución, el productor o fabricante conviene al suministro de un producto determinado al distribuidor, quien adquiere el producto para proceder a su colocación masiva por medio de su propia organización en una zona determinada [...]. De tal suerte el distribuidor actúa por su propia cuenta, $y$ a su propio nombre, intermediando en una actividad económica determinada que indirectamente relaciona al productor de bienes y servicios con el consumidor [...]. Colocando un eslabón en la cadena de comercialización de la mercadería. Por cierto, el apuntado hecho de que el distribuidor actúe en nombre propio lo permite distinguir del agente de comercio; asimismo, esa actuación por cuenta propia, hace que asuma los riesgos que de su actividad deriven [...] (C. Nac. Com., Sala D, 2010).

También se le define en sentido estricto como un contrato por medio del cual "el productor o fabricante acuerda con el distribuidor el suministro de un bien para su reventa en una zona determinada" (Soto, 1993, p. 31); similar opinión tiene Fontcuberta (2008):

Es de colaboración mercantil, atípico e intuito personae en virtud del cual un determinado empresario -distribuidorse compromete de forma duradera en el tiempo frente a otro -proveedor-a adquirir un volumen determinado de productos para revenderlos en nombre propio y por su cuenta y riesgo, en términos de exclusividad o no, debiendo, en su caso, seguir las instrucciones cursadas por el principal que, sin afectar a su independencia, le sean cursadas por este por lo que respecta al desarrollo de las actividades de promoción que correspondan (p. 121).

De acuerdo con lo anterior Hocsman (2007) propone que los elementos de este contrato son el territorio, la exclusividad y la duración; Marzorati (2008) agrega el control.

En síntesis, la distribución es un contrato que presenta las características de ser atípico en los términos que expone la Corte Suprema de Justicia (2002), intuito personae, con exclusividad de productos o de zona si así se establece, y con promoción estratégica ventilada con un formato único de propaganda, amén de la independencia jurídica del distribuidor asegurada por una duración a largo plazo (Farina, 2005).

\section{La explotación y la promoción en la distribución mercantil}

Como se hizo notar, el término 'explotar' necesariamente hace alusión al agente actuando como distribuidor, en caso de aceptarse ese tipo de figura jurídica. Adviértase de nuevo que este documento va en otra vía. La explotación es inmanente a la distribución, amén de su significado literal que es otro punto a favor de esta postura. Todo lo anterior tiene soporte en el hecho de que podríamos dirigirnos a la analogía (art. 1, Código de Comercio) para resolver el problema del concepto, en caso de que no se acepten otras definiciones, incluyendo la literal.

La razón para acudir a la analogía, como fuente de derecho mercantil, es la de dar una solución que en la propia ley no se encuentra, ya que la ayuda que podría brindar tanto la costumbre 
como la estipulación de las partes en el tema del agente-distribuidor, es prácticamente nula, de forma que la analogía puede ofrecer una salida pacífica; así vemos cómo el artículo 60 de la decisión 486/2000 expresa:

A los efectos del presente capítulo, se entenderá por explotación, la producción industrial del producto objeto de la patente o el uso integral del procedimiento patentado junto con la distribución y comercialización de los resultados obtenidos, de forma suficiente para satisfacer la demanda del mercado. También se entenderá por explotación la importación, junto con la distribución y comercialización del producto patentado, cuando esta se haga de forma suficiente para satisfacer la demanda del mercado. Cuando la patente haga referencia a un procedimiento que no se materialice en un producto, no serán exigibles los requisitos de comercialización y distribución.

Sumado a lo precedente es claro lo que el artículo 60 de la decisión 486/2000 revela en cuanto al término 'explotar'; más allá de que trate sobre la explotación de la patente, la norma es comercial, por lo que es totalmente aplicable lo que se conoce como analogía legis, es decir, funciona para integrar el entendimiento del vocablo 'explotar' que se estipula en la agencia mercantil; de esta forma podemos utilizar lo que el artículo 60 citado nos propone.

En síntesis, aceptado el término 'explotar' en este sentido o en su sentido literal, tal como lo determina el Código Civil para la interpretación de la ley, siempre acabamos en un mismo puerto: va ligado al contrato de distribución, únicamente.

\section{$V$. La promoción en la distribución como elemento natural del contrato}

Se entiende por promoción un conjunto de actividades que realiza el sujeto de comercio dentro del mercado, para crear, ensanchar y mantener la clientela. Para alcanzar sus fines se usa el marketing, la publicidad y la propaganda como un cuerpo estructurado para lograr que los productos sean aceptados por los consumidores.

La promoción hecha por el distribuidor la fija el productor, para que con su propio andamiaje empresarial coloque los productos en el mercado para su consumo. Es inherente a la actividad de venta del producto ${ }^{3}$, se ejecuta según varios métodos: folletos, propagandas en radio y televisión, acercamiento con los clientes, etc. Marzorati (2008) lo explica así:

[...] existe una planificación comercial, al establecer precios unitarios, régimen de mercados, aceptación y colaboración de un determinado programa de propaganda o publicidad, centralizado por el productor y compartido, en mayor o menor entidad $e$ intensidad, por el distribuidor, a lo que se une la obligatoriedad de tener establecimiento abierto, estacionamiento, depósito o inventario de un determinado número de productos manufacturados para atender el mercado que comprende la zona de influencia del distribuidor, etcétera (p. 80).

Ciertamente la promoción es un elemento natural de la distribución (1501 Código Civil), porque como ya se explicó, forma parte de la actividad del contrato tanto si es impuesta por el productor o el fabricante, como si es establecida por el propio distribuidor de acuerdo con su voluntad.

Al mismo tiempo la explotación actúa como elemento esencial derivándose de su ausencia la inexistencia jurídica del contrato de distribución (art. 898, Código de Comercio), lo cual marca un punto de diferenciación notable entre las características mencionadas en el seno de este contrato con respecto al agente, obviamente, incidiendo de modo negativo a la posición del agente-distribuidor.

En materia de sanciones se observa que para el agente el elemento promover es vital, tanto que

Como lo expresaba el derogado artículo 975 del Código de Comercio. 
la promoción es un requisito de la esencia del contrato, y su ausencia en la etapa de formación del contrato causaría la inexistencia del mismo. Explotar por otro lado, si ha de pertenecerle solo podrá ser por vía del consentimiento de las partes, reduciéndose en un elemento accidental del contrato, a lo sumo causando un incumplimiento contractual. Esta forma de entender las figuras es sencilla y efectiva y de la cual se puede observar una gran diferencia al leer estas desde el punto de vista de sus elementos esenciales, naturales $y$ accidentales.

\section{Distribución como clase de agencia comercial. Un punto de inflexión}

Existen opiniones que aceptan al agente-distribuidor, y es el promover o explotar el elemento fundamental para admitir dicha tesis; así lo expresa Arrubla (2004): "No todo el que distribuye es agente, pero el que lo hace mediante un encargo de promover o explotar negocios sí lo es" (p. 388). De igual forma este autor manifiesta:

Perfectamente puede presentarse la agencia comercial en concurrencia con un contrato de suministro, el cual se denomina frecuentemente en nuestro medio como contrato de distribución y aun de concesión, siempre con el encargo de promover o explotar negocios de un ramo. En este evento el agente será comprador de los productos de un fabricante y los venderá directamente a terceros (Arrubla, 2004, p. 388).

En la misma dirección encontramos a Alpiniano García (2001) cuando sostiene que "la distribución es accesoria y es permitida siempre que se haya dado junto con la colocación de los productos y la promoción de los mismos para generar o mantener la clientela" (p. 342). También en salvamento de voto de la sentencia dictada por el magistrado Pedro Lafont, se expresó que valdrá la pena analizar la posición de pactar para la agencia en modalidad de distribución, una remuneración adicional y así poder distinguirse de otras figuras (Corte Suprema de Justicia, salvamento de voto, 1995). Así mismo el profesor Pérez Vives (citado en Bonivento, 1999) declara:

Lo importante es que cuando quiera que un comerciante asuma el encargo de explotar o promover negocios de un empresario, estaremos frente a uno de los elementos del contrato de agencia, independientemente de que dicha promoción o explotación la realice como agente (sentido estricto), representante, distribuidor, fabricante o en cualquier otra forma que conduzca a la apreciación de estar dentro del marco legal que para la agencia comercial se ha en estos términos estatuido (p. 140).

No obstante, y siempre alrededor de la promoción, emerge otra forma de que los dos contratos puedan llegar a ser uno, o más bien, cómo el de agencia subsume al contrato de distribución. Suescún (2003) acoge esta interpretación:

Sin embargo, de acuerdo con lo previamente explicado, la "compra para revender" no impide la existencia de un verdadero agenciamiento, que aparece cada vez que el intermediario recibe el encargo de promover los negocios del fabricante y que dicha labor promocional se cumpla por cuenta, riesgo y en beneficio de este último. En consecuencia, la "promoción por cuenta" se erige como la verdadera diferencia específica y el elemento distintivo y más relevante de la agencia comercial. Por ende, el mencionado elemento esencial caracteriza al agenciamiento comercial y sirve de criterio diferenciador frente a otras figuras contractuales afines [...] El encargo para promover es realizado por el agente, bien en su propio nombre o en el del empresario, pero siempre por cuenta de este último, en el sentido de que dicha promoción ha de beneficiar primordialmente al agenciado. En este sentido, el elemento por cuenta tiene más un contenido económico que jurídico, pues se refiere a las ventajas o beneficios que obtiene el agenciado, los cua- 
les se derivan de la labor misma de contacto con los clientes potenciales y de persuasión para que adquieran los productos o servicios objeto de la promoción (pp. 469-470).

Todas las opiniones aunque distintas van hacia una misma dirección: la aceptación del agentedistribuidor; de modo que se tratan de explicar haciendo una suerte de análisis exegético de la norma sin tener en cuenta los efectos jurídicos que podrían resultar de tal combinación de figuras, de los cuales se mencionan algunos: (i) la confusión de los elementos promoción y explotación, sin analizar cómo deben manejarse en cada uno de los contratos, que valga decir, se desarrollan de una manera distinta; (ii) la aplicación de un régimen típico al distribuidor, cuando debe responder a un régimen atípico, conforme con su esencia; y (iii) la teoría del riesgo negocial también se maneja diferente en uno y otro contrato, es más, en el de agencia dicha tesis es prácticamente improcedente como se verá a continuación.

\section{Separación de la distribución y la agencia en la doctrina y en la jurisprudencia colombiana a partir de la teoría del riesgo negocial}

\section{Breve noción del riesgo negocial}

El sujeto que tenga la propiedad de un producto podrá ser responsable ante terceros. El riesgo jurídico se entiende como la contingencia de un daño potencial y es el elemento que estructura la responsabilidad (Sarmiento citado en Anaya, 2012).

Corsaro (citado en Anaya, 2012) expone que el riesgo se presenta como una conexión de un evento, como una actividad o como un acto; pero al mismo tiempo como una elección de la ley misma para hacer responsable a la persona que actúa sobre la probabilidad estadística de que el evento lesivo se haya producido como consecuencia de aquella actividad.
Pues bien, el riesgo que tiene un sujeto en el marco de los contratos de colaboración, como el de distribución, recae en el distribuidor, por la obtención del dominio del producto y, en principio, por la venta de los mismos a los consumidores. A este tipo de teoría, que también se muestra en la jurisprudencia colombiana, se le denomina teoría del riesgo negocial. En cuanto al riesgo negocial en el contrato de distribución Marzorati (2008) asegura:

Control: típicamente, el distribuidor es un empresario independiente que pone su empresa al servicio del fabricante; actúa en su nombre y por cuenta propia y no en representación del proveedor. El distribuidor adquiere la propiedad de los bienes cuando los obtiene de compra, con la consiguiente aplicación de la doctrina de los riesgos, por lo que el proveedor queda desvinculado de las sucesivas reventas que el intermediario realice, así como de la destrucción de la cosa, incluso por caso fortuito o fuerza mayor (p. 79).

En definitiva, el riesgo negocial es una noción emanada de la obtención de un producto dentro de una cadena de comercialización y como consecuencia de aquello, el propietario se beneficia o se perjudica por algunos aspectos que rodean ese producto en particular, como por ejemplo el alza o reducción de precios de acuerdo con lo que el mercado dicte al momento de reventa, y no al de obtención.

Se señala que el riesgo de los productos en la agencia le pertenece al empresario agenciado, salvo una redistribución del mismo (Mendieta, 2006); lo que es cierto, siempre que la agencia sea aceptada como un mandato y también sea empleada a nombre y por cuenta propia; pero la agencia, en principio, siempre es encargada y por cuenta ajena y a nombre del empresario nacional o extranjero, por cuanto el riesgo del producto no puede pertenecerle al agente, entre otras razones por la intermediación que ejecuta y además, porque tampoco tiene la capacidad de celebrar los negocios debido a que no le pertenecen los productos que promociona; luego 
entonces no pierde nada, y si no puede perder, tampoco puede arriesgar.

\section{El riesgo negocial: la separación de la distribución y agencia en la jurisprudencia colombiana}

La jurisprudencia colombiana se ha expresado suficientemente en relación con la separación de los contratos que están siendo estudiados. Creemos que los pronunciamientos giran alrededor de establecer la diferenciación de las figuras aludidas con base en la teoría del riesgo negocial, veamos:

La diferencia es bien clara: el distribuidor que actúa como agente comercial en nada lo benefician o perjudican las alzas o bajas que puedan sufrir los productos que promueve como quiera que la propiedad de estos en ningún momento del proceso de mercadeo pasa a ser suya, sino que del dominio del fabricante o empresario pasa al de la clientela sin que el agente tenga que adquirirlos. Por el contrario, cuando el distribuidor ha adquirido para sí los productos que promueve, resulta claro que un aumento en los precios de venta después de que sean suyos lo beneficia directamente, de la misma manera que lo perjudicaría una baja en las mismas circunstancias. El agente comercial, entonces, que distribuye, coloca en el mercado productos ajenos, no propios (Corte Suprema de Justicia, sentencia del 2 de diciembre de 1980).

En cambio, la actividad de compra para reventa de un mismo producto, solamente constituye el desarrollo de una actividad mercantil por cuenta y para utilidad propia donde los negocios de compraventa tienen por función la de servir a título de adquisición (en la compra) o la disposición (en la reventa) posterior con la transferencia de dominio mediante tradición. Pero el hecho de que para el cumplimiento de esta finalidad, el distribuidor tenga que efectuar actividades para la reventa de dichos productos, como la publicitaria y la consecución de clientes, ello no desvirtúa el carácter propio de aquella actividad mercantil, ni el carácter propio que también tiene la promoción y explotación de su propio negocio de reventa de productos suministrados por el empresario. Porque cuando un comerciante difunde un producto comprado para él mismo revenderlo, o, en su caso, promueve la búsqueda de clientes a quienes revenderles los objetos que se distribuyen, lo hace para promover y explotar un negocio que le es propio [...]. Por tal razón, para la Corte la actividad de compra hecha por un comerciante a un empresario que le suministra el producto a fin de que aquel lo adquiera y posteriormente lo distribuya y lo revenda, a pesar de que esta actividad sea reiterada, continua y permanente y que se encuentre ayudada de la ordinaria publicidad y clientela que requiere la misma reventa; no constituye ni reviste por sí sola la celebración o existencia de un contrato o relación de agencia comercial entre ellos (Corte Suprema de Justicia, sentencia del 30 de agosto de 1993).

En este estado del análisis se puede destacar que el riesgo negocial en uno y otro contrato más allá de cualquier elemento, es sustancialmente distinto, y la jurisprudencia así lo observa. En el mismo sentido continúa la Corte Suprema de Justicia (1995):

Por lo demás, la actividad de comprar bienes para luego revenderlos constituye la ejecución de una actividad mercantil por cuenta y para utilidad de quien la ejerce; y el hecho de que para el cumplimiento de tal propósito el distribuidor se vea precisado a desplegar ciertos actos de publicidad o de consecución de clientes, no desvirtúa, tal como lo ha sostenido esta Corporación, el carácter de acto propio de aquella actividad mercantil, por la sencilla razón de que quien distribuye un producto comprado por él mismo para revenderlo, lo hace para promover y explotar un negocio suyo, aunque, sin lugar a dudas, el fabricante se beneficie con la llegada del producto al consumidor final. 
En varias sentencias de la Corte Suprema de Justicia los magistrados Pedro Octavio Munar Cadena (2006), Ruth Marina Díaz (2008) y Fernando Giraldo Gutiérrez (2013) tratan sobre el riesgo negocial, insistiendo en que la actividad distributiva que se podría presentar en la agencia, por parte del agente, es para promover la colocación de productos del empresario, tanto que el éxito o el fracaso de los productos o del negocio en sí mismo se refleja en los estados financieros del encargante, mientras que el agente ya obtiene una remuneración establecida por la ley. Por su parte, en el laudo arbitral dictado en el proceso Preparación de Belleza S. A. vs. L'Oreal se consideró lo siguiente:

[...] el concesionario y el distribuidor son también promotores, pero la diferencia estriba en que adquieren para sí, en firme y definitivamente, las mercancías que les vende el empresario, y por tanto aquellos corren íntegros los riesgos de celebrar o no, negocios, los de pago y los que pesan sobre las cosas que poseen como propietarios (Tribunal de Arbitramento, 23 de mayo de 1997).

De igual manera, en el campo del arbitramento se ha mantenido casi la misma óptica utilizando como sustento la vía del riesgo negocial, tal como a continuación se expone:

Y en verdad que tal es la razón de ser de la agencia comercial: que el empresario, asumiendo los riesgos de la colocación de sus productos o servicios, entregue o descargue en otros los riesgos que implica el estructurar toda una empresa comercial para que el producto llegue al cliente y al mercado [...] En tratándose del contrato de agencia comercial es el empresario, no el agente, el que asume el riesgo en el negocio [...], es decir, que este asume las consecuencias patrimoniales, sean benéficas o adversas, ya que los efectos jurídicos realizados por el agente se "trasladan o deben trasladarse a la órbita patrimonial del dueño del negocio, de manera que es este quien está llamado a asumir los riesgos"
(Tribunal de Arbitramento, 1999, citado en Mendieta, 2006).

Y que finalmente, puede asumir el riesgo de la venta de sus propios productos, descargando en otro u otros el riesgo de los costos de la organización en las varias zonas. Es cuando surge el contrato de agencia. El agente comercial asume precisamente el deber de organizar a su propio riesgo y en condiciones de autonomía la colocación de los productos o servicios ajenos. Quien distribuye artículos que ha adquirido en propiedad, no obstante que fueron fabricados por otro, al realizar su venta en una determinada zona no ejecuta actividad de agente comercial, sino de simple vendedor o distribuidor de productos propios (Corte Suprema de Justicia, sentencia del 2 de diciembre de 1980).

El comportamiento del distribuidor es notoriamente distinto al del agente frente al producto, sobre todo atendiendo al riesgo negocial que trae a colación la Corte Suprema de Justicia, pues el empresario que encarga al agente solo lo hace para promover, sin que comporte traspasar los productos, mientras que en la distribución el fabricante siempre enajena los productos y con estos, el alea de los mismos, apareciendo en la esfera patrimonial del distribuidor.

Con la adquisición del producto se desprenden varios campos jurídicos de actuación, el primero es el del negocio mismo, por el cual el distribuidor en calidad de empresario independiente busca su lucro dependiendo de lo que dicte el mercado y cómo su producto ingrese a él, teniendo en cuenta sus precios y aceptación. En segundo lugar se marca la frontera entre el riesgo negocial y varios tipos de instituciones jurídicas, de las cuales se mencionan tanto a la responsabilidad originada de la ley 1480/2011 como a la teoría de los riesgos concretamente, fenómenos que operan concomitantes al alea del negocio.

Cabe señalar que la característica principal de la agencia es la intermediación (Valenzuela, 1997), y a partir de esta se indica que la posición que 
ocupa el agente dentro del contrato es única y sencilla: la de un comerciante en medio del empresario y el consumidor; su prestación se entiende de hacer en el marco de la agencia, la cual se circunscribe básicamente a la promoción de productos o servicios. El riesgo negocial por lo tanto forma parte de la esfera jurídica del empresario que encarga y no del agente encargado.

\section{Visión doctrinaria de la separación de la agencia y la distribución comercial}

En la doctrina extranjera la problemática que se suscita en Colombia no tiene asidero, ya que como se podrá ver, el contrato de agencia en otros países y según las tratativas que se disponen desde las respectivas leyes, contienen el elemento por cuenta y no la potestad de escoger el agente ser a un mismo tiempo distribuidor.

La diferencia es notoria, en especial cuando se dice que "el distribuidor actúa por cuenta propia y por tanto asume el riesgo empresarial de las operaciones en las que interviene. Esta característica es la que permite la diferenciación entre los contratos de agencia y de distribución [...]" (Soto, 1993, p. 31).

Las prestaciones de estas dos figuras se tornan interesantes a la hora de determinar la autonomía e independencia, así como la distinción que se causa al momento de explicar la naturaleza jurídica de las mismas, sin que por ello exista un grado de confusión entre ellas. El fundamento por supuesto, la promoción.

Resulta aún más fácil la distinción entre el contrato de distribución y el de agencia en tanto que el agente solo se compromete a desarrollar una actividad que tiende a la promoción de la comercialización de los bienes y/o servicios, a la captación de clientes y a la conclusión de negocios para su proponente, sin que ello le implique la compra de mercaderías que caracteriza al distribuidor. El agente es solo un intermediario entre el productor y el cliente (Hocsman, 2007, p. 84).
Para Marzorati (2008):

Ambos, distribuidor y agente, venden mercadería ajena. Pero el agente lo hace por cuenta y orden del principal; la relación jurídica en la cual se apoya su vínculo con el fabricante es el mandato. En cambio, el distribuidor vende a nombre propio y por su cuenta; le factura al cliente y lucra con la diferencia. [...] El agente y el distribuidor son formalmente independientes. El primero es un representante del fabricante o, incluso, del propio distribuidor. Este último, en cambio, compra y vende en forma repetida y masiva del fabricante, pero a nombre y por cuenta propia. El hecho de que el distribuidor actúe en nombre propio es lo que permite distinguirlo del agente de comercio (p. 82).

Del mismo modo alrededor del tema de la intermediación se aclara que "la actuación en nombre propio que caracteriza al distribuidor y al concesionario permite diferenciarlos del agente de comercio, pues este es solo un intermediario entre el productor y el cliente" (Farina, 2005, p. 499).

El contrato de agencia en Colombia presenta particularidades casi similares al contrato de distribución, tales como la estabilidad (Corte Suprema de Justicia, 1980), la independencia (López, 2011), el territorio y la utilidad por reventa o acompañamiento. Ello no quiere decir que sean los mismos negocios jurídicos. Esto también contribuye a la distinción, y no como erróneamente se cree, a su conjugación.

Para algunos es sencillamente inadmisible su conjugación por considerarse un error desde un punto de vista material y jurídico (Correa, 1991). Para ilustrar mejor este argumento y valga decir, con base en el encargo de promover y explotar, el profesor Gustavo de Greiff (citado en Bonivento, 1999) expresa:

Nada más erróneo. El objeto del contrato de agencia no es la actuación del agente por cuenta del agenciado. Si se lee atentamente 
el artículo 1317 del C. de Co., con ánimo desprevenido y no imbuido por tratadistas foráneos, se podrá apreciar que el objeto del contrato, es decir el fin o motivo del mismo, es que el comerciante independiente, cumpla con el encargo de promover o explotar negocios en un determinado ramo y dentro de una zona prefijada en el territorio nacional. Pero que haya un encargo no significa ni puede entenderse como que el encargado tenga que obrar por cuenta o a nombre del encargante; y tan es así, que la disposición citada, en su segunda parte dice cómo debe cumplirse ese encargo: "Como representante o agente de un empresario nacional o extranjero o como fabricante o distribuidor de uno o varios productos del mismo". Entonces, por las voces mismas del legislador se puede comprender que el encargo puede ser para actuar como representante o también como distribuidor $\mathrm{y} / \mathrm{o}$ como fabricante sin que tenga entonces que ser como tal.

La conjunción 'o' que usa el legislador es disyuntiva, nunca copulativa, y como tal denota separación, diferencia o alternativa. Por esto también está errado el segundo autor citado, el profesor Ramiro Rengifo cuando pretende distinguir entre la distribución por agente y la distribución en nombre propio, para sostener que solo la primera puede ser objeto del contrato de agencia pretendiendo con ello demostrar que la agencia requiere, como elemento de su esencia, el que se actúe como representante del productor, con lo cual incurre en el sofisma conocido como ex rebús que consiste en atribuir a la distribución por agente una calidad que no es propia de su esencia como es la de actuar el distribuidor por cuenta del productor (p. 143).

Se observa de la separación de dos entidades la contribución a la visión de la impertinencia de una figura inobservada. Se señala entonces que la distribución no puede ser por cuenta, ni el distribuidor puede representar al fabricante o productor; el distribuidor, entiéndase, siempre actúa por cuenta propia. No le responde al em- presario dado que el riesgo negocial recae en sus productos. Además, si se mira desde el punto de vista de la contratación en masa, no contribuye en nada aceptar un agente-distribuidor, pues aunque los contratos individualmente se presentan dentro de una cadena de comercialización, no es lógico hacer que un agente corra con los riesgos que el producto conlleva desde la perspectiva de los consumidores como quiera que le pertenece al empresario o fabricante.

Muy por el contrario, el distribuidor debe asumir el riesgo del negocio propio de distribución desde cualquier óptica y también en relación con los consumidores, en vista de que el fabricante no pretende tener en sí una clientela, sino más bien una buena reputación, la cual en muchos de los casos que involucran los contratos de colaboración mercantil, el distribuidor solo adquiere productos que ya poseen una marca sólida en el mercado.

Aquí vale la pena añadir un breve comentario sobre el tratado de libre comercio firmado con Estados Unidos en materia de agencia, puesto que sobre el agente-distribuidor no se dice nada, tan solo se reduce, como manifiesta López (2011), a entender el contrato de agencia tal como se consagra en los artículos 1317 a 1331 del Código de Comercio, es decir, el renombrado y especialísimo agente, debido a que los cambios a razón de los compromisos del Gobierno con Estados Unidos en algunas prescripciones de la agencia comercial, no se han surtido.

\section{E. La concurrencia contractual de la agencia con la distribución en la jurisprudencia colombiana}

La jurisprudencia colombiana admite la coexistencia de los contratos de agencia y distribución contribuyendo a la proscripción del agentedistribuidor, dada la necesidad de la prueba para determinar la utilización de cualquiera de los dos contratos.

Según la concurrencia un distribuidor que vende mercancías por cuenta y riesgo propio podrá 
establecer que también existe un contrato paralelo de agencia en la medida que pruebe la consecución de los elementos esenciales para ese contrato, valga decir, promover y explotar las ventas en claro beneficio de un empresario. A contrario sensu, si el contrato de distribución es el que se encuentra oscurecido en el ropaje de una agencia, también podrá establecerse la coexistencia siempre que se pruebe que hay ventas directas no encargadas por un empresario, o lo mismo, que se haga por cuenta propia. El laudo arbitral Colombina S. A. vs. Nestlé Purina PetCare de Colombia S. A. admite la coexistencia de los contratos, incluso, cuando se presentan los elementos de la agencia de hecho; en la misma línea la sentencia del 31 de octubre de 1995 expresa lo siguiente:

Es claro entonces que el contrato de agencia, no obstante su autonomía, su característica mercantil intermediadora, lo hace afín con otros contratos, con los cuales puede concurrir, pero sin confundirse con ellos razón por la cual, en este evento, su demostración tendrá que ser igualmente inequívoca.

No cabe duda que de alguna manera esta sentencia acepta la concurrencia contractual, puesto que en el mismo fallo hubo aclaración de voto reconfirmando este tema por parte del magistrado Javier Tamayo Jaramillo, el cual expresa:

[...] si el distribuidor que compra para revender, adicionalmente se obliga a ser el distribuidor oficial del suministrador, a representarlo ante las autoridades públicas, a realizar las campañas publicitarias y de demostración, a cumplir las garantías de calidad de los productos y en general, a realizar las gestiones que, en principio son las que habitualmente hace el mismo suministrador como un empresario diligente que quiere introducirse y mantenerse dentro del mercado, es indudable que, paralelo a la compraventa, se da el contrato de agencia mercantil, así todos los productos vendidos por el distribuidor hayan sido comprados por él al suministrador (Corte Suprema de Justicia, 31 de octubre de 1995).

Hay una pequeña corriente dentro de la Corte Suprema de Justicia que acepta la concurrencia contractual de la agencia con otras figuras, como ejemplo de esto la sentencia del 4 de abril de 2008 con ponencia de la magistrada Ruth Marina Díaz muestra la concurrencia de la agencia con otros negocios pero sin que ellos, dada la afinidad de características que tienen en común, puedan confundirse. La prueba en este punto es fundamental para determinar cuáles contratos son los que paralelamente subsisten, y desde esa óptica, al no permitir la confusión entre ellos tampoco se puede pretender que exista el agente-distribuidor, pues como ya se ha explicado el solo ente en materia de funciones es difuso.

La concurrencia que se propone no ha tenido tanta carrera ni judicial ni doctrinalmente, pero ello no significa que no aporte a la impropiedad del agente-distribuidor a partir de la proscripción de la confusión de negocios jurídicos afines.

En suma, la coexistencia contractual ayuda más a distinguir las actuaciones del agente de otros sujetos vinculados en otras relaciones jurídicas que por principios o características son semejantes pero no iguales. Una relectura del artículo 1317 del Código de Comercio, si se observa desde esta arista, se debe realizar si se acoge la hipótesis sobre que el agente-distribuidor es innecesario mantenerlo en nuestro ordenamiento jurídico mercantil por representar una figura confusa, en desuso e ininteligible.

\section{Conclusiones}

El agente-distribuidor es una creación legal a partir del artículo 1317 del Código de Comercio colombiano, el cual no debe implicar una aceptación absoluta dado lo evidenciado en las definiciones foráneas y lo expuesto por la doctrina nacional y extranjera; esto sin duda fue la pretensión principal: demostrar la existencia del agente-distribuidor y la impertinencia de dicha figura en Colombia. 
La jurisprudencia vertida en Colombia sobre la temática es exigua, porque siempre atiende otros temas sobre la agencia comercial, no obstante, da cierta explicación aunque vaga e imprecisa. Sobre esta base se puede inferir que la jurisprudencia no es unánime, y menos la doctrina colombiana en cuanto al agente-distribuidor. La definición de agencia en la jurisprudencia siempre concede a los elementos de promoción y explotación una explicación conjunta con la que pretende darle existencia jurídica al agente-distribuidor, lo que es un error dada la ligereza con que se trata el asunto; el agente, reitérese, solo promueve por cuenta de, y el distribuidor, promueve y explota para sí. El riesgo negocial en la agencia mercantil recae sobre el empresario encargante mientras que en el contrato de distribución sobre el distribuidor.

En suma, la teoría de la presencia de un agentedistribuidor en Colombia es útil académicamente para dar una explicación lógica a lo establecido en la ley, pero del todo inadecuada y confusa en cuanto al tratamiento que se configura alrededor del agente y el distribuidor, por lo que su impracticabilidad es patente. Se propone en aras de superar tal problemática, el inicio de una relectura del artículo 1317 del Código de Comercio mediante el cual la agencia se enmarque en su verdadera causa, que es la de promover para otro empresario, sin mezclarse con funciones de distribución.

Todo lo anterior apoyado en lo que se argumentó sobre la concurrencia de estos contratos, la adecuada utilización de los elementos esenciales en cada uno de estos negocios jurídicos y la comprensión del riesgo negocial de acuerdo con lo expuesto por la jurisprudencia colombiana.

\section{Referencias}

Anaya, C. P. (2012). Riesgos en las transacciones electrónicas bancarias. Una carga que debe ser asumida por la banca. Revist@ e-Mercatoria, 11(1). Disponible en: http:// www.emercatoria.edu.co/PAGINAS/VOLUMEN11/HTML1/136.html
Arrubla, J. A. (2004). Contratos mercantiles (8a ed.). Medellín: Biblioteca Jurídica Dike.

Baldi, R. (1987). Distributorship, franchising, agency, community and national law and practice in the ECC. Deventer: Kluwer.

Bonivento, J. A. (1999). Contratos mercantiles de intermediación ( $2^{\mathrm{a}}$ ed.). Bogotá: Ediciones Librería del Profesional.

Camacho, M. L. (2008). El contrato de agencia comercial, análisis dentro del contexto del sistema jurídico romano-germánico, en vista de una posible modificación de su regulación en Colombia.Revist@e-Mercatoria, 7(2). Disponible en: http://revistas. uexternado.edu.co/index.php?journal $=e$ merca\&page $=$ article\&op $=$ view\&path $\% 5$ B\%5D $=2042$ \&path\%5B\%5D $=1829$

Cárdenas, J. P. (1984). El contrato de agencia mercantil. Bogotá: Temis.

Código Civil Argentino. Capítulo XV, sección III del libro IV.

Comunidad Andina de Naciones. (2000). Decisión 486. Régimen común sobre propiedad industrial.

Correa, G. (1991). De los principales contratos mercantiles ( $2^{\mathrm{a}}$ ed.). Bogotá: Temis.

Corte Suprema de Justicia, Sala de Casación Civil. (1980). Sentencia del 2 de diciembre. M. P.: Germán Giraldo Zuluaga.

Corte Suprema de Justicia, Sala de Casación Civil. (1993). Sentencia del 30 de agosto. M. P.: Pedro Lafont Pianeta.

Corte Suprema de Justicia, Sala de Casación Civil. (1995). Sentencia de 31 de octubre. M. P.: Pedro Lafont Pianeta.

Corte Suprema de Justicia, Sala de Casación Civil. (2002). Sentencia del 13 de diciembre. M. $P$.: Carlos Ignacio Jaramillo.

Corte Suprema de Justicia, Sala de Casación Civil. (2005). Sentencia del 14 de diciembre. M. P.: Jaime Alberto Arrubla Paucar. 
Corte Suprema de Justicia, Sala de Casación Civil. (2006). Sentencia del 15 de diciembre. M. P.: Pedro Octavio Munar Cadena.

Corte Suprema de Justicia, Sala de Casación Civil. (2008). Sentencia del 4 de abril. M. P.: Ruth Marina Díaz.

Corte Suprema de Justicia, Sala de Casación Civil. (2013). Sentencia del 10 de septiembre. M. P.: Fernando Giraldo Gutiérrez.

Directiva del consejo de 18 de diciembre de 1986 relativa a la coordinación de los derechos de los Estados miembros en lo referente a los agentes comerciales independientes $(86 / 653 / \mathrm{CEE})$.

Farina, J. M. (2005). Contratos comerciales modernos ( $3^{\mathrm{a}}$ ed.). Buenos Aires: Astrea.

Fontcuberta, L. (2009). El contrato de distribución de bienes de consumo y la llamada indemnización por clientela. Madrid: Marcial Pons.

García, J. A. (2001). Derecho económico de los contratos. Bogotá: Ediciones Librería del Profesional.

Hocsman, S. (2007). Contratos modernos de distribución comercial. Buenos Aires: LexisNexis.

López, A. L. (2011). El contrato de agencia comercial y los cambios introducidos en la negociación del TLC entre Estados Unidos y los países andinos. Revist@eMercatoria, 10(1). Disponible en: http:// administracion.uexternado.edu.co/centros/ lp/der/results.asp

Marzorati, O. J. (2008). Sistemas de distribución comercial ( $3^{\mathrm{a}}$ ed.). Buenos Aires: Astrea.

Mendieta, J. A. (2006). Distribución del riesgo en el contrato de agencia comercial.Revist@
e-Mercatoria, 5(1). Disponible en: http:// administracion.uexternado.edu.co/centros/ $\mathrm{lp} / \mathrm{der} /$ results.asp

Narváez, I. (1976). Introducción al derecho mercantil. Bogotá: Ediciones Bonet.

Puelma, A. (1991). Contratación comercial moderna. Santiago de Chile: Editorial Jurídica de Chile.

República de Colombia. (16 de junio de 1971). Decreto 410. Por el cual se expide el Código de Comercio. Diario Oficial, 33.339.

Schmit, C. (1996). Sobre los tres modos de pensar la ciencia jurídica. Madrid: Tecnos.

Soto, R. A. (1993). Distribución comercial y derecho de la competencia. Disponible en: http://dialnet.unirioja.es/servlet/ revista?tipo busqueda $=$ CODIGO\&clave revista $=42 \overline{7}$

Suescún, J. (2003). Derecho privado, estudios de derecho civil y comercial contemporáneo (2a ed.). Bogotá: Legis.

Tribunal de Arbitramento. (1997). Laudo arbitral proferido el 23 de mayo. Proceso Preparación de Belleza S. A. vs. L'Oreal.

Tribunal de Arbitramento. (1999). Laudo arbitral proferido el 1 de septiembre. Proceso Faro Publicidad S. A. vs. El Colombiano Limitada y Cía SCA.

Tribunal de Arbitramento. (2005). Laudo arbitral proferido el 26 de mayo. Proceso Colombina S. A. vs. Nestlé Purina PetCare de Colombia S. A.

Valenzuela, F. J. (1997). El contrato de concesión mercantil y su extinción por denuncia unilateral. Revista de Derecho Mercantil, 225, pp. 1297 y ss. 